\title{
Typical Poverty Alleviation Models in Southern China and the Enlightenment to Jiangxi Province
}

\author{
Zheng Wang ${ }^{1, *}$, Zhiyan Zou ${ }^{2}$, Lei Guo ${ }^{3}$ \\ ${ }^{1}$ Department of Humanity, Jiangxi University of Finance and Economics, Nanchang, China \\ ${ }^{2}$ Faculty of Medicine, Nursing and Health Sciences, Monash University, Melbourne, Australia \\ ${ }^{3}$ Department of Public Administration, Nanjing Agricultural University, Nanjing, China
}

Email address:

wzwz789@hotmail.com (Zheng Wang)

${ }^{*}$ Corresponding author

\section{To cite this article:}

Zheng Wang, Zhiyan Zou, Lei Guo. Typical Poverty Alleviation Models in Southern China and the Enlightenment to Jiangxi Province. International Journal of Applied Agricultural Sciences. Vol. 4, No. 3, 2018, pp. 71-80. doi: 10.11648/j.ijaas.20180403.13

Received: June 15, 2018; Accepted: July 16, 2018; Published: August 14, 2018

\begin{abstract}
With China's poverty alleviation work at a crucial stage, poverty alleviation is mainly focused on the 14 concentrated destitute areas. In the Southern areas of China, there are numerous populations of poverty, wide range of poverty and the vast scale of poverty, which is a large proportion in the concentrated destitute areas. Among the Southern provinces of China, there are similarities of natural conditions, compatibility in cultural backgrounds and the complementation in economic structures. Therefore, there is the foundation of mutual learning or mutual cooperation in poverty alleviation work in China. This paper analyses the typical mode and experience of the crucial poverty-alleviation from Fujian, Guangdong, Guangxi and Guizhou provinces. Furthermore, based on reality situations, this paper puts forward the enlightenment of poverty alleviation to Jiangxi province. That is the poverty relief focus on spiritual power, the necessity of financial poverty relief facilitating industrial poverty relief, sufficient utilization of countryside tourism resources, targeted poverty relief among provinces or regions and emphasis on the role of big data in poverty alleviation, etc.
\end{abstract}

Keywords: Precision Poverty Alleviation, The Southern Provinces of China, Typical Models

\section{Introduction}

The 13th Five-Year Poverty Alleviation Plan of China has set the goal of eliminating poverty in rural areas would to achieve until 2020. The government of Jiangxi province also put forward to achieve the goal of poverty alleviation by 2018 . Nowadays, the poverty alleviation work in China has entered a critical stage, and how to get rid of poverty has become the focus of the whole society. Many problems in poverty appeared in Southern China, which is one of the main battlefields of poverty alleviation, such as the gap between the rich and the poor, the large number of the poor population and the complex causes of poverty. The four Southern provinces of Fujian, Guangdong, Guangxi and Guizhou, as the pioneers of poverty alleviation in Southern China, have explored many feasible poverty alleviation models. As the neighbor of the four Southern provinces, Jiangxi Province can learn from them in order to complete satisfactory the task of poverty alleviation in the last year. This paper selects four Southern provinces with great achievements in poverty alleviation work to analyze their typical poverty alleviation models in order to learn from their experiences and give enlightenments to the poverty alleviation work in Jiangxi Province.

\section{Purpose and Significance}

As the typical provinces in the work of poverty alleviation in Southern China, the four provinces of Fujian, Guangdong, Guangxi and Guizhou have similar natural conditions, cultural backgrounds and economic structures to Jiangxi Province. The typical models of poverty alleviation in these four provinces have great significance to the work of poverty alleviation in Jiangxi Province. 


\subsection{Similarity in Nature Conditions}

Jiangxi has nature conditions in common with the four provinces of Fujian, Guangdong, Guangxi and Guizhou, which are all located in similar latitude and longitude belonging to the tropical and subtropical climate zone, and they are rich in natural resources. The five provinces are adjacent to each other and have a wide range of communications.

\subsubsection{Landforms}

Table 1. The Area Proportion of Different Landforms in Jiangxi, Fujian, Guangdong, Guangxi, Guizhou Provinces.

\begin{tabular}{lll}
\hline Province & Type & Area Proportion (\%) \\
\hline \multirow{2}{*}{ Jiangxi } & Mountainous Area, & 36 \\
& Hilly Area & 42 \\
Fujian & Mountainous Area, & $>80$ \\
& Hilly Area & $>80$ \\
\multirow{3}{*}{ Guangdong } & Mountainous Area, & 35.3 \\
& Hilly Area & 27.4 \\
& Platform & 13.72 \\
\multirow{2}{*}{ Guangxi } & Mountainous Area, & 39.7 \\
& Hilly Area & 10.3 \\
\multirow{3}{*}{ Guizhou } & Platform & 26.9 \\
& Mountainous Area, & 92.5 \\
\hline
\end{tabular}

Source: Government websites and 2017 statistical yearbooks of Jiangxi, Fujian, Guangdong, Guangxi, Guizhou Provinces.

The landforms of five provinces are mainly mountainous and hilly area. The mountainous and hilly area of Jiangxi Province occupies $78 \%$ of the whole land. More than $80 \%$ areas are hilly mountains in Fujian Province. And the plain is more common in the eastern coast of Fujian Province. Guangdong Province has a variety of landforms with mountainous and hilly area, which occupied $62.7 \%$ of whole area. In that place, there are mountains and high hills in northern area, plains and platforms in Southern area. The landforms of Guangxi Province are mainly consist of mountainous, hilly and basin area, $50 \%$ of the whole area are mountainous and hilly area, while $26.9 \%$ are valley, plain and platform. The landforms of Guizhou Province can be classified into plateau mountain, hilly area and basin, and $92.5 \%$ are hilly area. The five provinces have similar landforms of mountainous and hilly areas, which make them have certain similarities in agricultural production.

\subsubsection{Climates}

The five provinces are all located in the subtropical climate zone where the weather is warm and humid. The average annual temperature of each province showed small difference. The average annual temperature of other four provinces is about $19.8^{\circ} \mathrm{C}$, except Guizhou province which is affected by plateau climate. The precipitation amount of these provinces is rich, no matter monsoon climate or oceanic climate, and the difference of annual precipitation amount is small. Similar climatic conditions in these five provinces have created the possibility of learning from each other for the development models of agriculture.

Table 2. Climates of Jiangxi, Fujian, Guangdong, Guangxi, Guizhou Provinces.

\begin{tabular}{llll}
\hline Provinces & Type & Average Annual Temperature $\left({ }^{\circ} \mathbf{C}\right)$ & Average Annual Precipitation Amount $(\mathbf{m m})$ \\
\hline Jiangxi & Subtropical Monsoon Climate & 18 & 1645 \\
Fujian & Subtropical Oceanic Climate & $17-21$ & $1400-2000$ \\
Guangdong & Subtropical Monsoon Climate & 21.8 & 1789.3 \\
Guangxi & Subtropical Monsoon Climate & $17.5-23.5$ & $842.1-3387.5$ \\
Guizhou & Subtropical Monsoon Climate & 16.4 & 1216.6 \\
\hline
\end{tabular}

Source: Government websites and 2017 statistical yearbooks of Jiangxi, Fujian, Guangdong, Guangxi, Guizhou Provinces.

\subsubsection{Natural Resources}

The cultivated land resources of the other four provinces are very rich, except that the cultivated area of Fujian Province is small. Mineral resources are very rich in the five provinces because of the complex geological structure. Among all the mineral resources identified, Jiangxi Province occupied 133 species, and Fujian, Guangdong, Guangxi and Guizhou Provinces occupied about 100 species. The excellent geographical location of the five provinces creates a good environment for human and nature. Also, the five provinces have a number of 5A-grade national tourist attractions, it can be inferred that these provinces are rich in tourism resources. The similar natural resources conditions of these five provinces makes that it is possible for Jiangxi Province to learn from the other four provinces in economic development and poverty alleviation.

Table 3. Natural Resources of Jiangxi, Fujian, Guangdong, Guangxi, Guizhou Provinces.

\begin{tabular}{lll}
\hline Provinces & Mineral Resources: Identified (species) & Tourist Resources: 5A-grade National Tourist Attractions (amount) \\
\hline Jiangxi & 133 & 10 \\
Fujian & 99 & 10 \\
Guangdong & 101 & 12 \\
Guangxi & 97 & 5 \\
Guizhou & 88 & 5 \\
\hline
\end{tabular}

Source: Government websites and 2017 statistical yearbooks of Jiangxi, Fujian, Guangdong, Guangxi, Guizhou Provinces.

\subsection{Compatibility in Cultural Backgrounds}

The result of the cultural compatibility among Jiangxi,
Fujian, Guangdong, Guangxi and Guizhou is that geographical location, migration and revolutionary war are combined action. With the development of history, it has 
evolved into contemporary Hakka culture, tea culture, red culture and ethnic culture. Under the influence of natural environment and social structure, they mix together and promote each other to compose an important part of Chinese culture.

The Hakka culture is one of the most special humanity and cultural factors of the five provinces. The Hakka mainly distributes in Jiangxi, Guangdong, Fujian, Guangxi, Guizhou Provinces, these provinces have deeply connection with Hakka culture because of historical reasons. The ancestors of Hakka lived in Central Plains in the past, they migrated to Southern China because of wars and famine. Ganzhou city in Jiangxi Province is the headstream of Hakka group. A few of Hakka moved from Southern of Ganzhou to Tingzhou city in Fujian Province, where is the capital of Hakka now. Meizhou city in Guangdong Province is the "Hakka City" of the world. A large number of Hakka ancestors moved into Meizhou from Tingzhou and Ganzhou, and finally completed the group amalgamation of Hakka here. [1]

As for the tea culture, the most representative elements are the industrialization of tea and the tea-picking opera. The five provinces have large-scale of tea cultivation because of similar natural conditions. By the end of 2015, Jiangxi Province had produced 52000 tons of tea, and the output of tea in other provinces is also very impressive according to Table 4 Tea-picking opera is originate from Ganzhou city in Jiangxi Province, and gradually spreads to the surrounding provinces like northeastern Guangdong and western Fujian. Tea-picking opera in Southern of Ganzhou is mainly developed from the combination of tea-picking lantern ${ }^{1}$ of Anyuan city in Jiangxi Province and tea-picking opera from eastern of Guangdong province. It has been recorded in the book of Wu Zhenfang Miscellanea of Guangdong: "Tea-picking lantern in Chaozhou which is the east of Guangdong was originally composed of twelve or eight people and chose two old people as the team leader. Then this form spread to the northern neighborhood which is Jiangxi Province..." [2]

Table 4. Tea Output in Recent 3 Years of Jiangxi, Fujian, Guangdong, Guangxi, Guizhou Provinces.

\begin{tabular}{llll}
\hline \multicolumn{4}{l}{ Tea Output (10000 tons) } \\
\hline Provinces & 2014 & 2015 & 2016 \\
Jiangxi & 4.43 & 5.19 & 5.75 \\
Fujian & 37.21 & 40.23 & 42.68 \\
Guangdong & 7.39 & 7.93 & 8.68 \\
Guangxi & 5.88 & 6.36 & 6.81 \\
Guizhou & 10.71 & 11.80 & 14.13 \\
\hline
\end{tabular}

Source: 2017 statistical yearbooks of Jiangxi, Fujian, Guangdong, Guangxi, Guizhou Provinces.

The boundary of Fujian, Jiangxi and Hunan Provinces were the main active areas of the Red Army in the past and that is also the origin of culture of red tourism. All the five provinces had famous old revolutionary bases, for example, the site of the Gutian Conference and the site of the Changting Revolution in Fujian Province; the site of the Yeping and the

1 A kind of folk song and dance originated from Longyan City, Fujian Province. site of Ningdu Uprising in Jiangxi Province; [3] the former residence of Marshal Ye Jianying and the former residence of Ye Ting in Guangdong Province; the site of the Seventh Red Army Department in Guangxi Province and the site of the Zunyi Conference in Guizhou Province. Those sites along with the revolutionary base of Jinggang Mountain and the Long March become a classic traveling route of red tourism across the five provinces.

Jiangxi, Fujian, Guangdong, Guangxi, Guizhou are all multi-ethnic provinces. Table 5 shows that each province has a certain number of ethnics and the species of the main groups are similar, which makes the communications of ethnic cultures among the five provinces closer. Ethnic culture background plays an important role in the poverty alleviation works, especially in pro-poor tourism. Jiangxi Province can learn from these four provinces on the method of poverty alleviation for helping the ethnics.

Table 5. Populations of Ethnics of Jiangxi, Fujian, Guangdong, Guangxi, Guizhou Provinces.

\begin{tabular}{llll}
\hline Provinces & Populations & Groups & Main Minorities \\
\hline Jiangxi & 44567797 & 54 & She, Hmong, Zhuang, Hui \\
Fujian & 36894217 & 55 & She, Hui, Tujia, Hmong \\
Guangdong & 104320459 & 55 & Zhuang, Hmong, Yao, Tujia \\
Guangxi & 46023761 & 55 & Zhuang, Yao, Hmong, Dong \\
Guizhou & 34748556 & 53 & Hmong, Bouyei, Dong, Yi \\
\hline
\end{tabular}

Source: calculated on the sixth census A0106a.

\subsection{Complementation in Economic Structures}

The development of economy is the most fundamental way for poverty alleviation. There is an objective factor in economic development which is imbalance among the five provinces. The differences of regional development level make the complementation in economic structures as an important part of poverty alleviation. The complementarity of these provinces is mainly manifested in the following aspects.

\subsubsection{Complementation in Labor Resources}

Table 6 shows that the quantity difference between the resident population and the household registered population of Jiangxi, Guangxi and Guizhou Provinces is negative and large, while that in Fujian and Guangdong Provinces is positive, especially in Guangdong Province, which is 1929.55 million. The table showed that the labor force of Jiangxi, Guangxi and Guizhou Provinces outflows because of underdeveloped economy, while the inflow of labor force in Guangdong and Fujian Provinces is more mainly because of rapidly economic development and the large demand of labor force.

Table 6. Resident Population, Household Registered Population and Their Difference of Jiangxi, Fujian, Guangdong, Guangxi, Guizhou Provinces.

\begin{tabular}{llll}
\hline Provinces & Resident Population & Registered Population & Difference \\
\hline Jiangxi & 44567797 & 47134135 & -2566338 \\
Fujian & 36894217 & 35371581 & 1522636 \\
Guangdong & 104320459 & 85024973 & 19295486 \\
Guangxi & 46023761 & 51591711 & -5567950 \\
Guizhou & 34748556 & 41600385 & -6851829 \\
\hline
\end{tabular}

Source: calculated on the total data of the sixth census. 


\subsubsection{Complementation in Natural Resources}

Although the five provinces are rich in natural resources, there are still some differences in demand and output. In Jiangxi Province, the reserves of copper, tungsten and silver are among the top three in China, and these mineral resources are essential to the industrial economy in other four provinces. As coastal provinces, Guangdong, Fujian and Guangxi are rich in marine resources, which are scarce in inland province like Jiangxi. Guizhou has the sixth largest storage of hydroenergy resources and the fifth largest coal reserves. The supply and consumption of resources in five provinces are complementary.

\subsubsection{Complementation in Scientific Technologies}

Table 7 shows that the ratio of R\&D investment in Jiangxi Province is lower than the national average level, and is lower than that in Guangdong and Fujian Provinces. Jiangxi Province is lack of professionals and weak in science and technology, while Guangdong and Fujian Provinces have strong scientific strength. They can learn from each other and help each other to reach the cooperation in the field of science and technology.

Table 7. The Expenditure of Research and Development (R\& D) in 2017 of Jiangxi, Fujian, Guangdong, Guangxi, Guizhou Provinces.

\begin{tabular}{lll}
\hline Provinces & R\& D Expenditure (100 million yuan) & R\& D Investment Proportion (\%) \\
\hline The Whole Nation & 15500 & 2.08 \\
Jiangxi & 201.1 & 1.1 \\
Fujian & 442 & 1.55 \\
Guangdong & 2003.7 & 2.52 \\
Guangxi & 117.74 & 0.64 \\
Guizhou & 73.4 & 0.62 \\
\hline
\end{tabular}

Source: National Statistic Bureau, 2017 national statistical bulletin of the expenditure of science and technology investment.

\subsubsection{Complementation in Industrial Structures}

From the analysis of Table 8 , it is concluded that Guangdong Province has the highest industrial structure and development level, followed by Fujian Province. The two developed provinces formed a industrial structure of "tertiary industry-secondary industry-primary industry". However, it has formed an industrial structure based on agriculture and industry, and dominated by tertiary industry in Jiangxi, Guangxi, Guangxi, Guizhou Provinces. The two developed provinces can use their superiorities on tertiary industry to help other provinces, and the other three provinces can output their secondary and primary industry to Guangdong and Fujian Provinces, the five provinces will make it possible to build a complementary relationship in the industrial structure.

Table 8. The Proportion of Industrial Structures of Jiangxi, Fujian, Guangdong, Guangxi, Guizhou Provinces.

\begin{tabular}{llll}
\hline \multirow{2}{*}{ Provinces } & \multicolumn{2}{l}{ Proportion of Industrial Structure (\%) } & \\
\cline { 2 - 4 } & Primary Industry & Secondary Industry & Tertiary Industry \\
\hline Jiangxi & 9.4 & 47.9 & 42.7 \\
Fujian & 7.6 & 48.8 & 43.6 \\
Guangdong & 4.3 & 43.4 & 52.0 \\
Guangxi & 14.2 & 45.6 & 40.2 \\
Guizhou & 14.9 & 40.2 & 44.9 \\
\hline
\end{tabular}

Source: calculated on 2017 statistical yearbooks of Jiangxi, Fujian, Guangdong, Guangxi, Guizhou Provinces.

\section{Characteristics of Typical Models of Poverty Alleviation in Southern China}

Chapter 2 analyses the typical models and their characteristics of poverty alleviation from Fujian, Guangdong, Guangxi, Guizhou provinces, including 8 models - Ningde model and financial poverty alleviation model in Fujian Province; "double to" model in Guangdong Province; ecosystem poverty alleviation model, first-line officials model and inter-province mutual assistance model in Guangxi Province; rural pro-poor tourism model and big data poverty alleviation model in Guizhou Province.

\subsection{Characteristics of Typical Models of Poverty Alleviation in Fujian Province}

Fujian Province is located in the southeast coast of China, with mountainous and hilly landforms, which is also a major ethnic habitation in China. Its natural conditions and cultural backgrounds led to the imbalanced development between coastal areas and inland areas. This situation is very similar to Southern Jiangxi Province, so the typical poverty alleviation models of Fujian Province can be taken as a reference in poverty alleviation work of Jiangxi Province.

\subsubsection{Ningde Model}

Ningde is a coastal city located in the northeast of Fujian Province, with mountainous and hilly landforms. The multi-ethnic population structure and the history of revolution make it a sample of the poverty alleviation in Fujian Province. When the President Xi Jinping worked in Ningde, he put forward five ideas about poverty alleviation, which formed the Ningde Model. First, "Weak birds can fly first", poverty-stricken areas should pay more attention to their own development. The weak side needs more time and energy to become strong. Second, as a sustainable way to overcome poverty, education is the most essential factor in the process of 
poverty alleviation. Third, persistence is the key to overcome poverty, no matter how difficult it is, no one will give up. Fourth, officers should come to the first-line to go deep among the people. Fifth, the government should choose a suitable way according to reality when take measures to overcome poverty. [4]

Changing mind is the first thing to get rid of spiritual poverty. President Xi Jinping mentioned that "Weak birds can fly at first, the poor may become rich at first". [5] Poor people should change their cognition of poverty and try to improve the status actively. As the core of Eastern Fujian Spirits, persistence is an essential factor in the process of poverty alleviation. To overcome the poverty, the government should work together with public to improve the current situation, this may take a long time but everyone should insist on it and all the people will live a better life in the future.

Education and science technology play an important role in Ningde model. There are many policies like developing the vocational education and improving people's cultural quality. Also, the government has formulated training classes for village officials, attracted the skilled personnel in the process of production to teach and guide the poor famers. By combining agricultural production with science technologies, local farmers developed a large ecological agricultural industry according to local conditions.

The guidance of officials is a key to poverty alleviation. The Ningde government had been encouraged officials to come to the first-line, interview every household to know their difficulties and needs since 1988. In the past three decades, they solved countless problems for people, and provide suitable methods to overcome poverty according to the situations of different households in poor areas.

\subsubsection{Financial Poverty Alleviation Model}

From 2007 to now, the farmer micro-finance in Pingnan County, Fujian Province has reached great achievements. As an important part, the Farmer Micro-finance Promotion Association works as intermediary. On the one hand, the promotion associate cooperates with the rural financial institutions to transfer the funds in order to meet the financial demands of farmers like increasing the credit limitation. On the other hand, the promotion associate works together with the government to transfer the information of farmers in order to know their financial demands and control the credit risks. The structure of farmer micro-finance has three points: the financial institutions, the farmer micro-finance promotion association and the government. The tripartite cooperation makes the farmer micro-finance more equally and effectively. At the same time, the marketing operation of funds and the informationization of personal credit make a better management of micro-finance. The farmer micro-finance in Pingnan County as a typical model of financial poverty alleviation model in Fujian Province, it has some superiorities like the tripartite cooperation of the financial institutions, the farmer micro-finance promotion association and the government; the informationization of personal information and financial demands; the guidance and management of government and institutions. [6]

The government of Fujian Province has put forward five suggestions on the farmer micro-finance: first, strengthening the identification of poor farmers and meeting their financial demands; second, improving financial services; third, developing various of financial products and promoting the farmer micro-finance in the whole province; fourth, providing more support and relaxing the entry standards; fifth, establishing and improving the financial service system for poverty alleviation and promoting the coverage of financial services in all poor areas. [7]

\subsection{Characteristics of Typical Models of Poverty Alleviation in Guangdong Province}

Some poor areas still exist in Guangdong Province which is the richest province in China. The current poverty phenomenon is imbalanced development between Pearl River Delta of China in Southern Guangdong Province and other areas result in the poverty of areas outside Southern in Guangdong Province. In the National People's Congress (NPC) and the National Committee of the Chinese People's Political Consultative Conference (CPPCC) of Guangdong Province, poverty alleviation has been focused. As a developed province, Guangdong has strong economic strength to make several attempts in poverty alleviation, and accumulated rich experiences and contributed to the poverty alleviation work in China. The concept of "double to" is "be responsible to every household and people in poverty". This model requires taking targeted measures in poverty alleviation to help every household and people in poverty to live a better life. The "double to" model includes many aspects like poverty alleviation by developing rural industry, financial poverty alleviation, pro-poor tourism, poverty alleviation by science and technology, inter-region mutual assistance and poverty alleviation by the whole society.

Poverty alleviation by developing rural industry is an important part of poverty alleviation work in Guangdong Province. With the support of local government, leading enterprises bring capitals to poor areas and develop characteristic industries depending on local conditions. These local characteristic industries can promote local economic development and provide career opportunities for people in poverty. Taking the Guangdong Silk-tex Group as an example, which is the leading enterprise of sericulture industry. The Guangdong Silk-tex Group built a factory in Liannan County, which provides opportunities for poor farmers planting mulberry and raising silkworm. [8] The group develops sericulture industry in Liannan County according to the local natural environment superiorities, and promotes the transformation and upgrade of Liannan regional industry. At the same time, this group combined the culture of sericulture with the local ethnic culture, integrated the cultural elements into the industry, increased the value of agricultural products, promoted the local economic development.

There are still some problems of financial poverty alleviation in Guangdong Province. Rural financial institutions are mainly concentrated on developed towns, and 
it is difficult to meet the demands of people in poor areas with urgent financial needs. Financial poverty alleviation is not worked in poor areas because of backward financial infrastructures. In order to ensure the accurate flow of funds and meet the needs of the poor, the government should carry out the "double to" idea-be responsible to every household and people in poverty. The government of Guangdong Province encourages private capital to join in financial poverty alleviation, provides more support and investment in finance, locates the poor in need and completes their personal information, builds more financial institutions such as country banks.

Guangdong Province is rich in tourism resources and the undeveloped eastern and northwestern parts have excellent conditions for pro-poor tourism. The government of Guangdong Province has invested a large amount of funds to develop pro-poor tourism in poor areas, and took some measures like setting up provincial key projects of pro-poor tourism, developing tourism resources according to local conditions, strengthening infrastructure construction and creating tourism culture with local characteristics. The government has explored a new model of pro-poor tourism combined local culture with tourism resources together. Recently, the government published a list of demonstration areas of local cultural tourism, created influential cultural tourism brands and built cultural industrial parks in these areas.

As a new poverty alleviation model in Guangdong Province in recent years, there are still some weaknesses in poverty alleviation of science and technology. It is difficult for the scientific equipment and professionals to reach the isolated and poor areas because of inconvenient traffic and lacking of communications. The government ignored the importance of science and technology in poverty alleviation, so the project developed slowly because of fund shortage. The development of this model needs more hardworking of talents, while there is a shortage of scientific professionals. The Department of Science and Technology of Guangdong Province published the "Plan for Poverty Alleviation by Science and Technology in Three Years" in 2016. The plan calls for popularizing scientific production in poor areas, sending technical personnel to the first-line to help the poor, establishing a service platform for poverty alleviation by science and technology and speeding up the process of informatization. [9]

The inter-region mutual assistance requires the cooperation between coastal developed cities and the poor areas. At first, the mutual assistance only includes the economy assistance, and the both sides are large areas like provinces. With the processes of "double to" model, the mutual assistance includes many fields like constructions, industries and public services. The participants in cooperation relationship are becoming more detailed, which is between cities and districts.

Poverty alleviation by the whole society is a new way and a supplement of poverty alleviation. As the main force in the whole society, social organizations, on the one hand, linked with various social institutions to ask for their support; on the other hand, called on all the public to join the poverty alleviation by the whole society. The charities and religious groups in Guangdong Province developed very well. They contributed to the poverty alleviation work by their own strength, offered supports to the poor like donating living materials. Nowadays, however, the "double to" model requires the society to change the way of helping the poor. "Give a man a fish and you feed him for a day. Teach him how to fish and you feed him for a lifetime."The most useful way to overcome poverty is a sustainable development for poverty alleviation.

\subsection{Characteristics of Typical Models of Poverty Alleviation in Guangxi Province}

Guangxi, an inland province with mountainous and hilly landforms and a history of revolutionary wars, is also one of the biggest ethnic habitations in China. Guangxi has a weak economic base and a large number of poor people. The poverty area mainly locates in the western and northern parts, which are isolated mountain areas. [10] The poor natural environment is the main cause of poverty in Guangxi Province.

\subsubsection{Ecosystem Poverty Alleviation Model}

The poor areas of Guangxi Province are mostly in isolated mountains and stony desertification areas in the western and northern parts. The extremely natural environment makes the poverty alleviation work difficult to carry out. Guangxi province accounts for the largest area in the stony desertification area of Yunnan, Guangxi and Guizhou Provinces, one of the 14 concentrated destitute areas in China. The ecosystem poverty alleviation model is necessary in order to solve the poverty in Guangxi Province.

In isolated mountainous areas which the natural environment is adverse, people's living conditions are tough, and it is difficult to develop agricultural production. Local economic development cannot rely on the natural environment, the poverty cannot be solved entirely. The first step in ecosystem poverty alleviation is environmental migration, which is including methods of relocation, labor export and eco-education migration. The poor areas are not suitable for human habitation, which will reset to areas with better environment. They are encouraged to receive education and trained to improve the living environment with the help of the government. The second step is ecological management. It is necessary to restore the environment of stony desertification areas, and to improve the natural conditions of stony desertification areas while preventing the further expansion of it. The third step is ecological protection, to prevent the destruction of natural environment in stony desertification areas and to maintain the sustainable development of ecology in poor areas.

\subsubsection{First-Line Officials Model}

The first-line officials are usually outstanding party members and administrative staffs from public institutions and state-owned enterprises. The government organizes and encourages these officials to come to the first-line of poverty 
to help the poor. This is an innovative model of poverty alleviation.

The first-line official work as a bridge of communication between the government and the poor, to ensure that the situation and demands of the poor can be transmitted to the government directly, and the policies can be carried out more efficiently better to the poor. The government of Guangxi province sent college-graduated village officials to serve as first-line officials to help local governments formulate more scientific and accurate to poverty alleviation measures according to local conditions. The first-line officers should create innovative and typical products in their jurisdictions and guide the poor to overcome poverty. The first-line officials took a series of measures, such as strengthening infrastructure constructions, to develop local industries, to popularize rural micro-finance and to carry out labor training for farmers. The government of Guangxi Province has set up the first "First-line Officials Industrial Park" in China, combining the achievements of first-line poverty alleviation with industrial poverty alleviation, and exhibiting the products of the impoverished counties. This is a new way for the poor to sale their characteristic agricultural products. [11]

\subsubsection{Inter-Province Mutual Assistance Model}

China has established a poverty alleviation model of East-West cooperation encouraging the eastern developed provinces to help the western poor provinces since 1996. In recent years, Guangxi Province and Guangdong Province have established a new poverty alleviation model of inter-province mutual assistance. As neighborhoods, the two provinces established cooperation relationship. Relying on the strong economic strength of Guangdong Province, the economic growth in poor areas in Guangxi has been promoted.

In the cooperation of two provinces, Guangdong Province provided strong support to Guangxi Province. Firstly, the government of Guangdong Province donates a large number of money and materials, and helped Guangxi Province in infrastructure constructions. The government of Guangdong Province carried out a "whole village promotion" project in Guangxi Province to help every village to overcome poverty by financial aid and technical support. Secondly, strengthening the economic and trade cooperation between the two provinces. Guangdong Province has a superior geographical position and a long history of foreign trade. The government shares good trade resources and markets with Guangxi Province to promote the economic development in Guangxi Province. At the same time, labor export was carried out to encourage the labor force of Guangxi Province to flow to Guangdong Province, which increased the employment rate of the poor in Guangxi Province. Thirdly, the two provinces established an inter-province mutual assistance cooperation in poverty alleviation. The developed areas in Guangdong Province cooperated with the poor areas in Guangxi Province, the two governments communicate frequently to share the experience of poverty alleviation and strength cooperation in vocational education and labor training.

\subsection{Characteristics of Typical Models of Poverty Alleviation in Guizhou Province}

Guizhou Province is focus of poverty alleviation in China. In 2016, 50 counties in Guizhou Province were listed on the list of poor national counties, which shows the severe situation of poverty in Guizhou Province. Guizhou is an inland province located in isolated mountainous areas, and inhabited by multiple ethnics. Guizhou occupies a large proportion of the 14 concentrated destitute areas in China, and the causes of poverty is so complex that the poverty alleviation work in Guizhou Province facing great challenges. With years of hardworking, Guizhou Province has gradually explored the poverty alleviation model adapted to the local conditions on the road of overcoming poverty.

\subsubsection{Rural Pro-Poor Tourism Model}

Guizhou Province has a beautiful natural environment, some distinctive ethnic culture has been complete protected and inherited because of their habitation geographical locations are isolated. Based on the characteristics of various primitive villages, multiple ethnics and rich tourism resources, the rural pro-poor tourism model has become one of the main models of poverty alleviation in Guizhou Province. The government of Guizhou Province established many state-level pro-poor tourism villages to help the poor to overcome poverty and become rich through tourism.

As Leishan County of Guizhou Province an example, that is one of the state poverty counties with $82 \%$ of the total population of the Hmong. Leishan County remains the traditional culture of the Hmong with beautiful environment and rich tourism resources. Depending on the advantages of local conditions, Leishan County developed the rural pro-poor tourism model and built ethnical tourist villages--"Xijiang Hmong Villages". In the process of developing the rural pro-poor tourism, those living under the poverty line should be positioned to ensure that the rural pro-poor tourism allowance sent to people in need, enterprises are encouraged to participate in the rural pro-poor tourism, relevant professionals are cultivated, the series of actions aim to ensure the sustainable development of rural pro-poor tourism. [12] The government of Leishan County combined agritainment and industrial parks with rural pro-poor tourism model to promote the development of agricultural characteristic industries with tourism. The tea industry is one of the agricultural characteristic industries in Leishan County with the development of rural pro-poor tourism, the small-scale tea cultivation has been developed into industrial chains of planting and processing. The government combined the ethnical culture with the local tourism resources, created characteristic tourism brands of ethnical culture to increase the value of local products. The government combined the culture, tourism and agricultural industries to form a model of "one industry (tourism) drives three production (three main industries)".

\subsubsection{Big Data Poverty Alleviation Model}

Poverty alleviation by big data is a new strategy of Guizhou 
Province. The "Big Data" and the "Big Poverty Alleviation" are the tow main movement of the Thirteenth Five-year Plan in Guizhou Province. The government of Guizhou Province created a new concept of "Poverty Alleviation Plus" based on the "Internet Plus", developed cloud computing of poverty alleviation to establish the informationization of poverty alleviation data. [13] The big data technology has many functions like positioning the poor and creating files for them, analyzing the causes of poverty, establishing a communication net for related administrations to share the data of poverty alleviation, monitoring the process of poverty alleviation and the fund flow.

As the old revolutionary bases of Guizhou province an example, it has a long history of revolution and is rich in red tourism resources. But the old revolutionary bases are often poor areas, poverty alleviation in these areas is very important. Firstly, making a survey about the situation of the old revolutionary bases is used by big data, which are the information of the poor, the source and destination of poverty alleviation fund. Secondly, transforming and upgrading the industry in old revolutionary bases, combining the red tourism industry with the green ecological agricultural industry, and planning the red and green industries through the big data cloud computing platform. Finally, the education of science and technology in the old revolutionary bases is developing to change the traditional concept of poverty alleviation.

To popularize the concept of big data in poor areas, it is necessary to improve the construction of infrastructure, perfect communication and network equipment, strengthen the quality education, to combine the big data technology with local industries to promote the development of e-commerce in poor areas. Guizhou Province has gained achievements in the research and exploration of big data poverty alleviation model, which makes this model become a new pattern of poverty alleviation in China.

\section{Enlightenments of Poverty Alleviation in Fujian, Guangdong, Guangxi and Guizhou Provinces}

As neighborhoods of Jiangxi Province, the four provinces of Fujian, Guangdong, Guangxi and Guizhou have similarity in nature conditions, compatibility in cultural backgrounds, complementary in economic structures with Jiangxi Province. The government of Jiangxi Province can learn from the poverty alleviation experiences of the four provinces.

\subsection{Attach the Importance to Spiritual Strength in the Process of Poverty Alleviation}

The construction of spiritual civilization is vital in poverty alleviation. Jiangxi Province should learn from Ningde Model to change the concept of poverty. The main cause of poverty in many areas is the poverty of spirit, those living under the poverty line often think that they cannot change the status, their backward thoughts lead to their uncooperative and doubtful attitude towards poverty alleviation policies. Jiangxi
Province should change the concept of people to achieve the aim of spiritual poverty alleviation first and foremost. The change of concept should include three parts: the government, the enterprises and the public. Firstly, the local government should change the backward political consciousness and focus on the spiritual poverty alleviation work. The government can build the civilization demonstration villages through household propaganda, voluntary service and cultural activities. Secondly, the enterprises should change the backward business philosophy and take their social responsibilities. The enterprises should join in the poverty alleviation work and combine the enterprise culture with spiritual poverty alleviation to use their superiorities in industry to help the people in poverty through donating materials and providing career opportunities. Thirdly, the public should change their thoughts of being satisfied with the current situation. The public, especially the poor, should be encouraged to join in the poverty alleviation. The exemplary personnel of agricultural production and the successful model of poverty alleviation can be invited to join the voluntary teams to help the people still in poverty.

Another main cause of poverty in Jiangxi Province is the low level of education. Most people in poverty only received the primary education or even illiterate, the lack of education leads to the limitation of the development of economy. Therefore, the government of Jiangxi Province should pay more attention to the development of education and improve the cultural quality of the public in order to reduce the possibility of returning to poverty in the future.

\subsection{The Necessity of the Cooperation of Industrial Poverty Alleviation and Financial Poverty Alleviation}

Though always be ignored, financial poverty alleviation still occupies an indispensable position in poverty alleviation work. Comparing with the developed photovoltaic industry, forestry and fruit industry and other characteristic industries according to the local conditions in Jiangxi Province, the effect of financial poverty alleviation is weak. Jiangxi Province should pay attention to the development of financial poverty alleviation, combine financial poverty alleviation with industrial poverty alleviation. The finance can give economic support to the development of industries and encourage the poor farmers to start a business. Jiangxi Province should learn from the "double to" model to be responsible for every household and people in poverty to take targeted measures to help people overcome poverty.

On the one hand, the government should combine financial poverty alleviation with local industries to develop financial service products to meet the financial demands of poor farmers and bring the insurance into the financial poverty alleviation to develop agricultural insurance against the risks of local industries. On the other hand, the government should support the development of rural finance through preferential policies such as financial subsidies and tax preferences, establish the financial service system of "agriculture, rural areas and farmers" and promote inclusive finance in rural areas. It is necessary to relax the entry standards of 
micro-finance to attract more poor farmers to receive this financial service and to encourage poor farmers to start their own businesses. Under the support of financial poverty alleviation, a new model of industrial poverty alleviation-"one village, one products" is formed, which means that every village should develop characteristic industries and products based on the local conditions.

\subsection{Developing the Rural Tourism Resources and Regional Culture of Jiangxi Province}

Jiangxi Province has a beautiful natural environment, a long history and rich tourism resources to develop pro-poor tourism for poverty alleviation. About $80 \%$ of tourism resources in Jiangxi Province is in rural areas, with 125 primitive villages, 116 famous towns and villages of provincial level, 121 A-grade rural tourist attractions including natural tourism resources, red tourism resources and ethnical tourism resources. Jiangxi Province has numbers of A-grade national tourism attractions like Mountain Lu, Mountain Sanqing, Mountain Longhu, Poyang Lake etc. [14] To develop the natural tourism resources properly can increase economic growth and help the poor to overcome poverty. The old revolutionary bases in Jiangxi Province are the most potential part of red tourism resources with historical cultural backgrounds. The government can develop the red tourism resources in Nanchang, Ganzhou, Ruijin and Jinggangshan Cities and establish a net of red tourism attraction in the province to promote the process of poverty alleviation in old revolutionary bases and spread the Red Spirit of our party. Jiangxi Province is also an ethnic habitation in China with multiple ethnics and colorful ethnical cultures. The government should utilize the ethnical cultures to develop ethnical tourism and cooperate with Fujian and Guangdong Province to establish tourism projects of Hakka cultures. It is also very important to protect the environment in the process of developing tourism resources, utilize resources properly and develop a sustainable industry chain of pro-poor tourism.

\subsection{Exploring the Inter-Province and Inter-Region Mutual Assistance Model}

Except for own efforts, the process of poverty alleviation can be promoted with the help of developed provinces and regions. Jiangxi Province can cooperate with the developed neighboring provinces which are Guangdong and Fujian to explore the inter-province mutual assistance model. In the process of mutual assistance and cooperation, the government of Jiangxi Province should change the former unidirectional way of poverty alleviation and form a win-win partnership to promote the economic development of both sides. Jiangxi has complementary characteristics in many aspects with Guangdong and Fujian Provinces in terms of natural resources and industrial structures. Jiangxi Province can promote the economic development through industry, finance and science technology with the support of developed province. Jiangxi Province should prepare for industrial transfer to improve industrial structures and to enhance industrial advantages. The government of Jiangxi Province should learn the experience of financial poverty alleviation in developed provinces and cooperate with financial institutions in developed provinces to make the fund flow between provinces. The government should learn from the experience of production technology in developed provinces and invite scientific and technological professionals from developed provinces to give suggestions on the poverty alleviation work in Jiangxi Province. Similarly, the government should establish an inter-region mutual assistance to encourage developed cities such as Nanchang and Ganzhou to help the poor areas to accelerate the process of poverty alleviation in Jiangxi Province.

\subsection{Applying the Big Data Technology in Poverty Alleviation}

Internet technology is one of the main powers for the development of social productivity. Nowadays, the informationization and datamation played an important role in the field of poverty alleviation, therefore, the big data has become a new way to poverty alleviation. The big data technology in Jiangxi Province is lack of popularization, and the poverty alleviation work in Jiangxi Province has some problems such as low accuracy and narrow coverage. Therefore, the government should attach great importance to the role of big data technology in promoting precision poverty alleviation in Jiangxi Province. The government of Jiangxi Province should learn from the experience of the big data poverty model of Guizhou province to master the big data technology and establish a poverty alleviation monitoring system. In further process of precision poverty alleviation, it is necessary to build the big data network, promote the poverty alleviation informationization, position the current situation of poverty, monitor the future trends of poverty, supervise and manage the fund of poverty alleviation, innovate the poverty alleviation service system and share the information of poverty alleviation work. Through the application of big data technology, the process of precision poverty alleviation will speed up in Jiangxi province.

\section{Conclusion}

This paper analyzes the typical poverty alleviation models of the four Southern provinces and puts forward the suggestions for spiritual poverty alleviation, industrial poverty alleviation, financial poverty alleviation, pro-poor tourism, inter-province mutual assistance and big data poverty alleviation combined with the present situation of Jiangxi Province. In this paper, there are only 1 or 2 typical poverty alleviation models in each province are studied because of the limited length, and there are still have some shortcomings which we hope to improve in the future research. Poverty alleviation requires the participation of all social forces, such as governments, enterprises, organizations and the masses, as well as the help of spirit, industry, finance, resources, science and technology. Rome was not built in a day, which means not only the Jiangxi Province but also the whole country should learn from experiences, help each other and seek sustainable 
development on the road of poverty alleviation, and reduce the possibility of returning to poverty in the future.

\section{Acknowledgements}

This paper is a part of general projects of the National Social Science Fund of China-- Study on Medical Security Mechanism of Rural Empty Nest Under the Background of New-type Urbanization in China (14BJY157). In the process of the study, I want to express my appreciation to everyone who has helped me for the kindness.

Firstly, I appreciate all the members in my group for discussing, researching and translating. Some of them are still students but helped me a lot, like searching for documents and analyzing the data.

Secondly, my sincere appreciation also goes to the colleagues of the School of Humanities of Jiangxi University of Finance and Economics for their valuable advice.

Lastly, I shall extend my thanks to the anonymous reviewers for your hard working and thorough attitude towards the paper.

\section{References}

[1] Zhong Shenghong, Huang Dequan. The Influence of Hakka Culture Ecological Effect on Regional Development in Guangdong, Fujian and Jiangxi Provinces. Human Geography 2009, 2, 60-62.

[2] Wu Zhenfang. Miscellanea of Guangdong. The Commercial Press 1936.

[3] Zheng Haiyan. A Study on the Sustainable Development of Hakka Cultural Tourism from the Perspective of Regional Cooperation: A Case Study of the Border Among Fujian, Guangdong and Jiangxi Provinces. Forward Position 2011, 4, 135-138.
[4] Liao Xiaojun. My opinion on the "Ningde Model" of Poverty Alleviation. Mindong Daily 2016-02-04, A01.

[5] Xi Jinping. Up and Out of Poverty. Foreign Languages Press 2017.

[6] Zheng Shouming, Wu Zixing, etc. Research on Financial Innovation from the Perspective of Precision Poverty Alleviation: A Case Study of Pingnan Micro-finance Promotion Association. Southwest Finance 2016, 7, 59-62.

[7] Ministry of Finance of the People's Republic of China. Suggestions on the Assistance of Financial Aid to the Poverty Alleviation 2016-03-24.

[8] Zheng Hailong, Li Linshan, etc. Development of Sericulture Industry and Establishment of Sustainable Poverty Alleviation Model: Practice and Experience of Industrial Poverty Alleviation Model of Guangdong Silk-tex Group in Liannan County. Guangdong Sericulture 2012, 46, 14-17.

[9] Department of Science and Technology of Guangdong Province. Plan for Poverty Alleviation by Science and Technology in Three Years. Office of Poverty Alleviation and Development of Guangdong Province 2016-10-12.

[10] $\mathrm{Wu}$ Yuxiong. Concentrate on the Key Point of Poverty Alleviation. Guangxi Daily 2015-03-11.

[11] Li Yuntao, Rong Xingqiao. The Government of Guangxi Province Has Set Up the First "First-line Officials Industrial Park" in China. China Business Times 2016-03-29, 006.

[12] Wu Yaping, Chen Pinyu, etc. Research on the Pro-poor Tourism of Ethnical Villages and Study on the "Integration of Agriculture and Tourism" in the Pro-poor Tourism of Ethnical Villages in Guizhou Province. Journal of Guizhou Normal College 2016, 32, 57-61.

[13] Yang Guang. Guizhou Province: Using "Cloud" to Help Poverty Alleviation. People's Weekly 2016, 9, 16-17.

[14] Zhu Hong. Promoting the Rural Tourism and the Pro-poor Tourism. Contemporary Jiangxi 2015, 11, 8-9. 